\title{
Five new species of Polycentropodidae (Trichoptera) from Ecuador and Venezuela
}

\author{
STEVEN W. HAMILTON ${ }^{1} \&$ RALPH W. HOLZENTHAL ${ }^{2}$ \\ ${ }^{1}$ Austin Peay State University, The Center for Field Biology, P. O. Box 4718, Clarksville, Tennessee 37044, \\ U.S.A. (hamiltonsw@apsu.edu) \\ ${ }^{2}$ University of Minnesota, Department of Entomology, 1980 Folwell Ave., Room 219, St. Paul, Minnesota \\ 55108,U.S.A. (holze001@umn.edu)
}

\begin{abstract}
Diagnoses, descriptions and illustrations of male genitalia are given for four new species of the Polycentropus gertschi group, Polycentropus cressae n. sp., Polycentropus neblinensis n. sp., Polycentropus quadricuspidis n. sp., and Polycentropus silex $\mathrm{n}$. sp. The former two are from Venezuela and the latter two from Ecuador. In addition, a diagnosis, description and set of male genitalia illustrations are provided for Polyplectropus beccus, a new species from Ecuador. The generic placement of this species, while currently appropriate, may require reclassification pending completion of ongoing studies on Neotropical polycentropodids.
\end{abstract}

Key words: Trichoptera, Polycentropodidae, Polycentropus, Polyplectropus, caddisfly, new species, Neotropics, Ecuador, Venezuela

\section{INTRODUCTION}

The cosmopolitan caddisfly family Polycentropodidae comprises approximately 600 recognized species (ITIS 2002, Morse 2001). As currently defined, the genera Polycentropus sensu stricto and Polyplectropus are global in distribution and include 158 and 145 species, respectively (ITIS 2002). Flint et al. (1999) recorded 64 species of Polycentropus sensu lato (they did not separate Polycentropus sensu stricto from possible Plectrocnemia) and 42 species of Polyplectropus from the Neotropics. Recent investigations have added 6 Polycentropus and 10 Polyplectropus to the known Neotropical fauna (Chamorro-Lacayo 2003, Holzenthal \& Almeida 2003, Chamorro-Lacayo \& Holzenthal 2004, Flint \& Sykora 2004). Ongoing investigation in Central and South America will more than double the known Neotropical Polyplectropus (Chamorro-Lacayo \& Holzenthal 2004) and add more than 2 dozen Polycentropus (Holzenthal \& Almeida 2003). 
Four of the following new polycentropodids are Polycentropus of the gertschi speciesgroup. In his study of the Neotropical Polycentropus s. s., Hamilton (1986) identified 3 synapomorphies that support monophyly of the gertschi group: (1) the ventral process of the phallobase is apicoventral in position, (2) each intermediate appendage is free to its base and articulates basomesally on its preanal appendage, and (3) there is a sclerite formed in the membrane below and around the phallus that appears to support and guide this organ. Two of the new species described here, Polycentropus cressae n. sp. and Polycentropus neblinensis $\mathrm{n}$. sp., both from Venezuela, are placed in the picana complex of the gertschi group. The picana complex is identified by 2 synapomorphies: (1) short tubular portion of the phallobase and (2) 2 groups of spines in the phallic membranes (Hamilton 1986). Species of the picana complex include Polycentropus aztecus Flint, Polycentropus bellus Flint, Polycentropus gertschi Denning, Polycentropus lingulatus Flint, Polycentropus picana Ross, Polycentropus veracruzensis Flint, and Polycentropus zanclus Flint.

From Ecuador, Polycentropus quadricuspidis n. sp. is placed in the joergenseni complex based on the occurrence of a dorsal sclerotized band in the phallic membrane (Hamilton 1986). This species complex includes Polycentropus connatus Flint, Polycentropus exsertus Flint, Polycentropus hamiferus Flint, Polycentropus joergenseni Ulmer, Polycentropus longispinosus Schmid, Polycentropus meridiensis Flint, Polycentropus uribici Holzenthal \& Almeida and nearly 2 dozen undescribed species from southeastern Brazil. Based on illustrations, it appears that Polycentropus sarandi Angrisano is a member of this complex and related to the species from southeastern Brazil.

Polycentropus silex n. sp., also from Ecuador, is placed in the bartolus complex based on the presence of a single, large spine in the phallic membrane (Hamilton 1986). Other members of the bartolus complex are Polycentropus alatus Flint, Polycentropus azulus Flint, Polycentropus bartolus Denning, Polycentropus ceciliae Flint, Polycentropus dentoides Yamamoto, Polycentropus encera Denning \& Sykora, Polycentropus fasthi Holzenthal \& Hamilton, Polycentropus fortunus Flint, Polycentropus holzenthali Bueno \& Hamilton, Polycentropus mayanus Flint, and Polycentropus unispina Flint. Polycentropus nebulosus Holzenthal \& Hamilton was also placed in this complex by these authors (1988) in spite of having 3 large phallic spines rather than the single spine.

A 5th polycentropodid described here is tentatively placed in the genus Polyplectropus based on wing venational characters including the strongly recurved apical portion of $\mathrm{Cu} 2$ that is only tenuously connected to the posterior margin of the forewing and the absence of fork I in the hind wing. Nonetheless, the male genitalia are not typical of known Neotropical Polyplectropus (Chamorro-Lacayo, personal communication). Resolution of generic classification of this new species is left to Maria Lourdes Chamorro-Lacayo, University of Minnesota, St. Paul, Minnesota, who is currently investigating the genus Polyplectropus and its placement in the Polycentropodidae.

Procedures for preparation and illustration of male genitalia and wings and for construction of species description follow those described by Holzenthal \& Andersen (2004). 
Types are deposited in the collections of the National Museum of Natural History, Smithsonian Institution, Washington, DC (NMNH) and the University of Minnesota Insect Col-

lection, St. Paul, Minnesota (UMSP) as indicated in the species descriptions.

\section{SPECIES DESCRIPTIONS}

\section{Polycentropus cressae Hamilton and Holzenthal, new species} Fig. 1

Polycentropus cressae $\mathrm{n}$. $\mathrm{sp}$. is similar to $P$. aztecus, $P$. gertschi and $P$. neblinensis $\mathrm{n}$. $\mathrm{sp}$. in the possession of a single pair of anterior spines in the phallic membranes below the phallic sclerite (Fig. 1E \& F) in addition to another more mesal group of spines. In P. cressae and $P$. neblinensis, the anterior (basal) pair of spines is large and reminiscent of bull's horns. In P. cressae, the spines in the mesal group (Fig. 1E \& F) are less numerous (3540) and larger than those in P. neblinensis (>50). Polycentropus aztecus and P. gertschi have a single pair of spines in the anterior group that are notably smaller and more similar to those in the mesal group and those in the mesal group are 4 and 6 in number, respectively.

Polycentropus cressae is unique in the number of heavier mesal spines in the phallic membranes (ca. 35-40; Fig. 1E \& F), the lateral flanges on the posterior margins of the phallobase (Fig. 1E), the narrow ventromesal process of the phallobase with a shallow apical emargination (Fig. 1E \& F), the narrow lateral face of the inferior appendage (Fig. 1A), and the simple triangular shape of the preanal appendage in lateral view (Fig. 1A).

Adult. Length of forewing: male 6.5-7.0 mm ( $\mathrm{n}=3)$, female 7.5-8.2 $\mathrm{mm}(\mathrm{n}=2)$. Body pale brown to yellow, legs stramineous, dorsum of head and thorax brown, clothed with long, dark setae; general vestiture of forewing with fine, brown to dark brown setae, with many scattered areas of golden setae, base of forewing with long, erect setae.

Male. Genitalia as in Fig. 1. Sternum IX in lateral view subtriangular, in ventral view quadrate; anterior margin shallowly concave, posterior margin slightly produced medially. Tergum IX and X membranous. Intermediate appendage straight, slightly angled basally, short, exceeding preanal appendage by less than 1/4th its length; basal region simple, not expanded; apex digitate, with apical setae. Preanal appendage short, densely setose, triangular, broad basally; mesoventral process absent. Inferior appendage densely setose, short, subtriangular, wide dorsoventrally, subequal to length; dorsolateral flange narrowly rounded; ventrally with dorsally-directed caudomesal point, exposed in lateral view; in ventral view, inferior appendage subtriangular, caudomesal point prominent, acute; in caudal view, inferior appendage subtriangular, caudomesal point broadly triangular. Phallobase very short, apicolateral corner produced into short flange; apicoventral projection long, narrow, with pair of points; phallic membranes with anterior and mesal groups of spines (although probably reversed in evaginated phallus), anterior group consisting of 
zоотаха long, paired, curved spines, mesal group of many (35-40) small spines; phallic sclerite 810 oval (difficult to discern, especially apically). Subphallic sclerite U-shaped in caudal view.
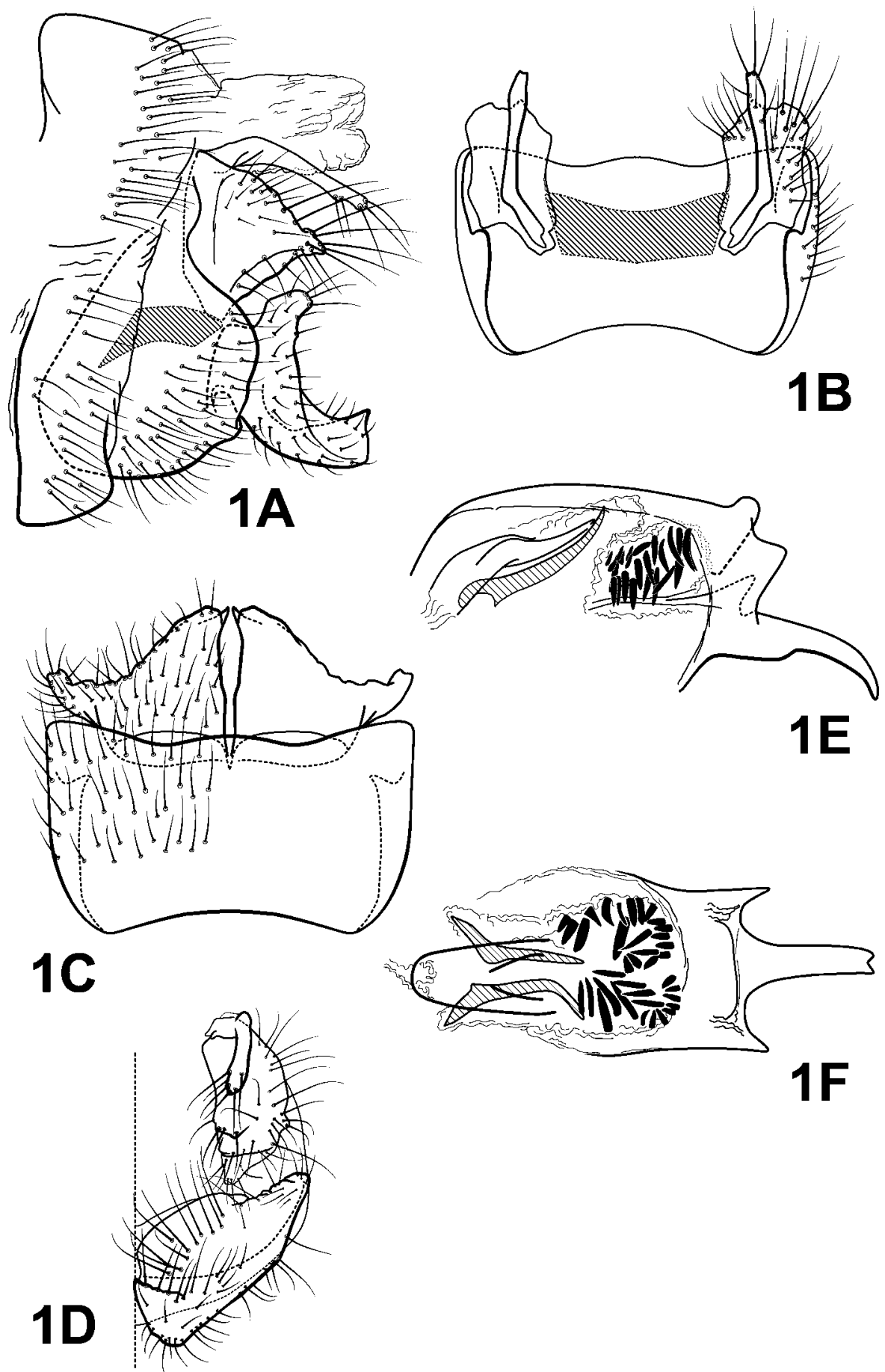

$1 E$

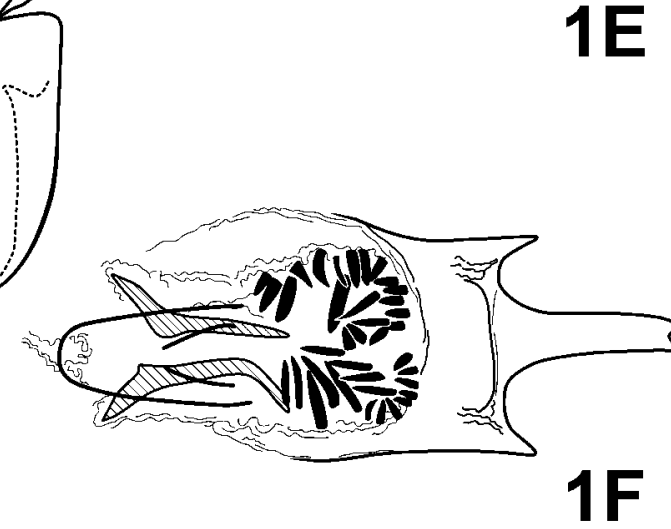

FIGURE 1. Polycentropus cressae, new species. Male genitalia: A-lateral; B-dorsal; C—ventral; D—caudal; E-phallus, lateral; F-phallus, dorsal. 
Holotype male. VENEZUELA: Falcón: P[arque]. N[acional]. Sierra de San Luis, Paprocki, Cressa (UMSP000074848) (UMSP)

Paratypes: Same data as holotype-1 male, 1 female (UMSP), 1 male, 1 female (NMNH).

Etymology. We take great pleasure in naming this species in honor of Dr. Claudia Cressa, Universidad Central de Venezuela, in recognition of her contributions to the study of Venezuelan aquatic insects and her generous support of our work in Venezuela.

\section{Polycentropus neblinensis Hamilton and Holzenthal, new species}

Fig. 2

Polycentropus new species 11, Hamilton 1986: 130-131, 231, fig. 6.37.

Similar to Polycentropus cressa, n. sp., P. aztecus and P. gertschi in the possession of a single pair of anterior spines in the phallic membranes, P. neblinensis $n$. sp. differs from all 3 in the large number and small size of the mesal group of spines in the phallic membrane (Fig. 2E). It is similar to P. cressa and further distinguished from P. aztecus and P. gertschi in the large, bull's-horn appearance of the anterior pair of phallic spines (Fig. 2E). The prominent emargination of the shorter apicoventral process of the phallobase (Fig. 2G) is unique. In addition, the shape of the inferior appendage in lateral (Fig. 2A) and ventral views (Fig. 2C) and the lateral view of the preanal appendage (Fig. 2A) distinguishes $P$. neblinensis from these and the other species of the picana species complex.

Adult. Length of forewing: male 7.0-9.0 mm ( $\mathrm{n}=9)$, female 9.5-11.0 mm ( $\mathrm{n}=3)$. Body pale brown to yellow, legs stramineous, dorsum of head and thorax brown, clothed with long, dark setae; general vestiture of forewing with fine, brown to dark brown setae, with many small, scattered areas of golden setae, base of forewing with long, erect setae.

Male. Genitalia as in Fig. 2. Sternum IX in lateral view subtriangular, in ventral view quadrate; anterior margin shallowly concave, posterior margin slightly concave. Tergum IX and X membranous. Intermediate appendage slightly curved mesad, short, exceeding preanal appendage by less than 1/4th its length; basal region simple, not expanded; apex digitate, with apical setae. Preanal appendage short, densely setose, triangular, broad basally; mesoventral process broadly triangular, directed ventrally, apex bluntly triangular. Inferior appendage densely setose, short, oval, dorsoventral height greater than length; dorsolateral flange broadly rounded; ventrally with dorsally-directed caudomesal point, exposed in lateral view; in ventral view, inferior appendage subquadrate, caudomesal point prominent, rounded; in caudal view, inferior appendage quadrate, caudomesal point triangular. Phallobase moderately short; apicoventral projection long, broad, with pair of points; phallic membranes with anterior and mesal groups of spines (although probably reversed in evaginated phallus), anterior group consisting of long, paired, sigmoid spines, 

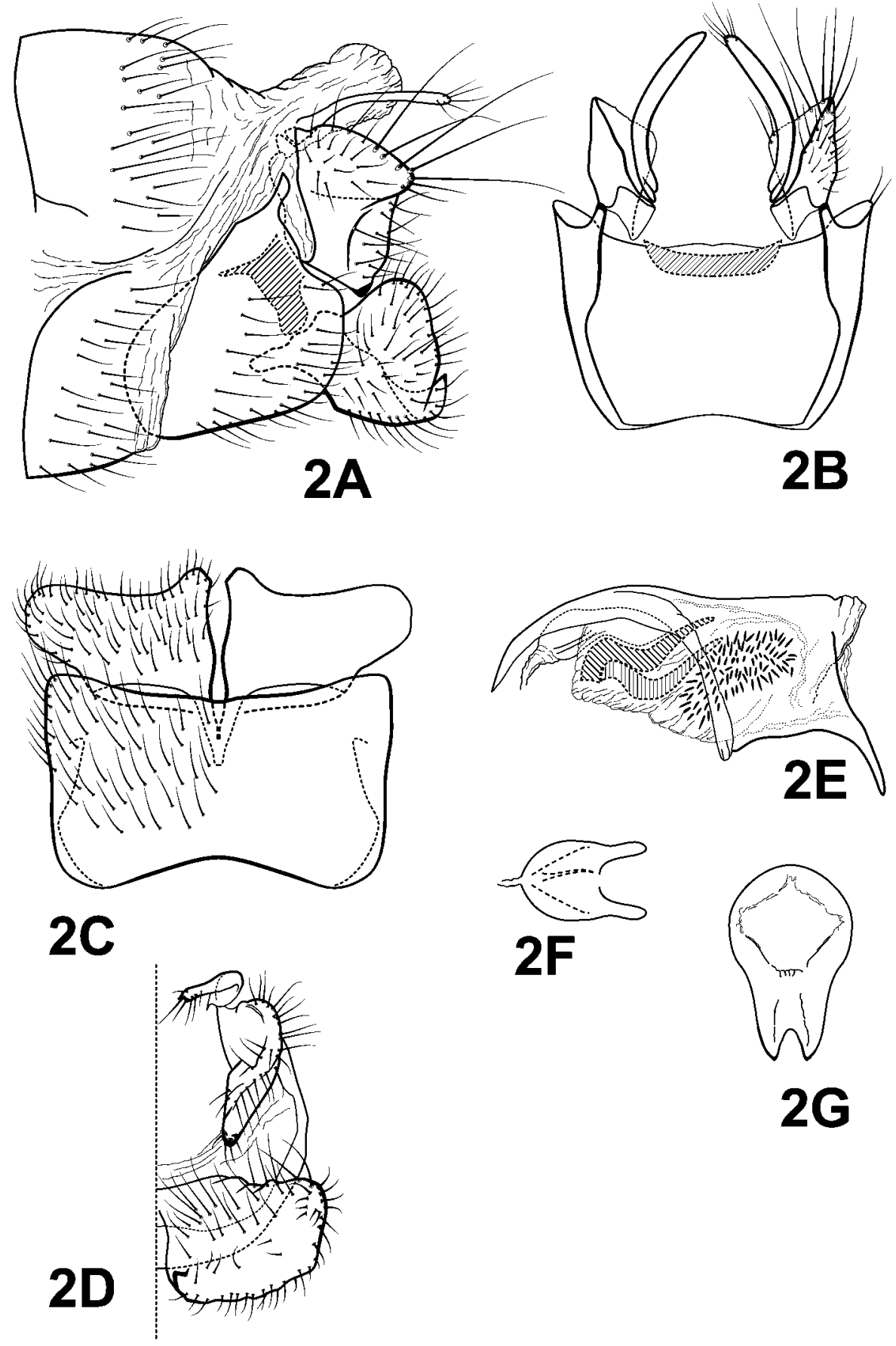

FIGURE 2. Polycentropus neblinensis, new species. Male genitalia: A-lateral; B-dorsal; Cventral; D—caudal; E—phallus, lateral; F—phallic sclerite, dorsal; G—phallobase, caudal. 
Holotype male: VenezUELA: Amazonas: Cerro de la Neblina, Camp II, 004' N, 6559'W, el. 2100 m, 16-18.iii.1984, J.A. Louton (NMNH).

Paratypes: Same data as holotype, except $00^{\circ} 50^{\prime} \mathrm{N}, 29 . \mathrm{i} .1985$, at blacklight at edge of open bog and Bonnetia scrub, W.E. Steiner-2 males (NMNH); same as holotype, except Camp III, 0056'10"N, 6603'53"W, el. 1820 m, 15-17.ii.1984, D. Davis-2 males, 1 female (UMSP); same as holotype, except Camp VII, $00^{\circ} 51^{\prime} \mathrm{N}, 65^{\circ} 58^{\prime} \mathrm{W}$, el. $1850 \mathrm{~m}, 30$. i- $^{-}$ 10.ii.1985, P.J. and P.M. Spangler, R.A. Faitoute, at blacklight -2 males NMNH); same as last, except 2-4.xii.1984, R.L. Brown-1 female; same as holotype, except Camp X, $00^{\circ} 54^{\prime} \mathrm{N}, 60^{\circ} 02^{\prime} \mathrm{W}$, el. $1690 \mathrm{~m}, 13 . i i .1985$, W.E. Steiner, at blacklight, mixed scrub forest near stream and canyon rim-2 males (NMNH); same as last, except 12.ii.1985-1 female (NMNH).

Etymology. The species epithet is derived from Cerro de la Neblina, the tepui from where this species was collected.

\section{Polycentropus quadricuspidis Hamilton and Holzenthal, new species}

Fig. 3

From Ecuador, P. quadricuspidis n. sp. is placed in the joergenseni complex and is most closely related to $P$. joergenseni $i$ and $P$. longispinosus. These 3 species share 4 synapomorphies not found in other species of the joergenseni complex: (1) a ventral sclerotized band in the phallic membranes (Fig. 3E), (2) a pair of ventral sclerotized bumps in the phallic membrane apical to the ventral band (Fig. 3E), (3) an apicoventral process on the phallobase that is reduced to a pair of ventral points (Fig. 3E \& G), and (4) somewhat broadened and flattened inferior appendages (Fig. 3A). The inferior appendage of $P$. quadricuspidis (Fig. 3A \& C) is shorter than that of $P$. longispinosus and resembles that of $P$. joergenseni. The intermediate appendage (Fig. 3A \& B) is intermediate between that of P. longispinosus and P. joergenseni in both length and thickness. Polycentropus quadricuspidis is most easily distinguished from these sister species by the 2 pairs of apicoventral points on the phallobase (Fig. 3G), the more prominent, spicule-covered pair of ventral bumps in the phallic membranes (Fig. 3E), and the slight dorsal concavity of the lateral face of the inferior appendages (Fig. 3A).

Adult. Length of forewing: male $9.0 \mathrm{~mm}(\mathrm{n}=2)$, female $8.0 \mathrm{~mm}(\mathrm{n}=1)$. Body stramineous, legs stramineous, dorsum of head and thorax brown, clothed with long, dark setae; general vestiture of forewing with fine, brown to dark brown setae, with many small, scattered areas of golden setae, base of forewing with long, erect setae.

Male. Genitalia as in Fig. 3. Sternum IX in lateral view subquadrate, posterolateral corner slightly produced, in ventral view slightly trapezoidal; anterior margin concave, posterior margin slightly concave. Tergum IX and X membranous. Intermediate appendage sinuate, apex curved medially, long, exceeding preanal appendage by more than $1 / 2$ its length; basal region simple, not expanded; apex acuminate, without apical setae. Preanal 

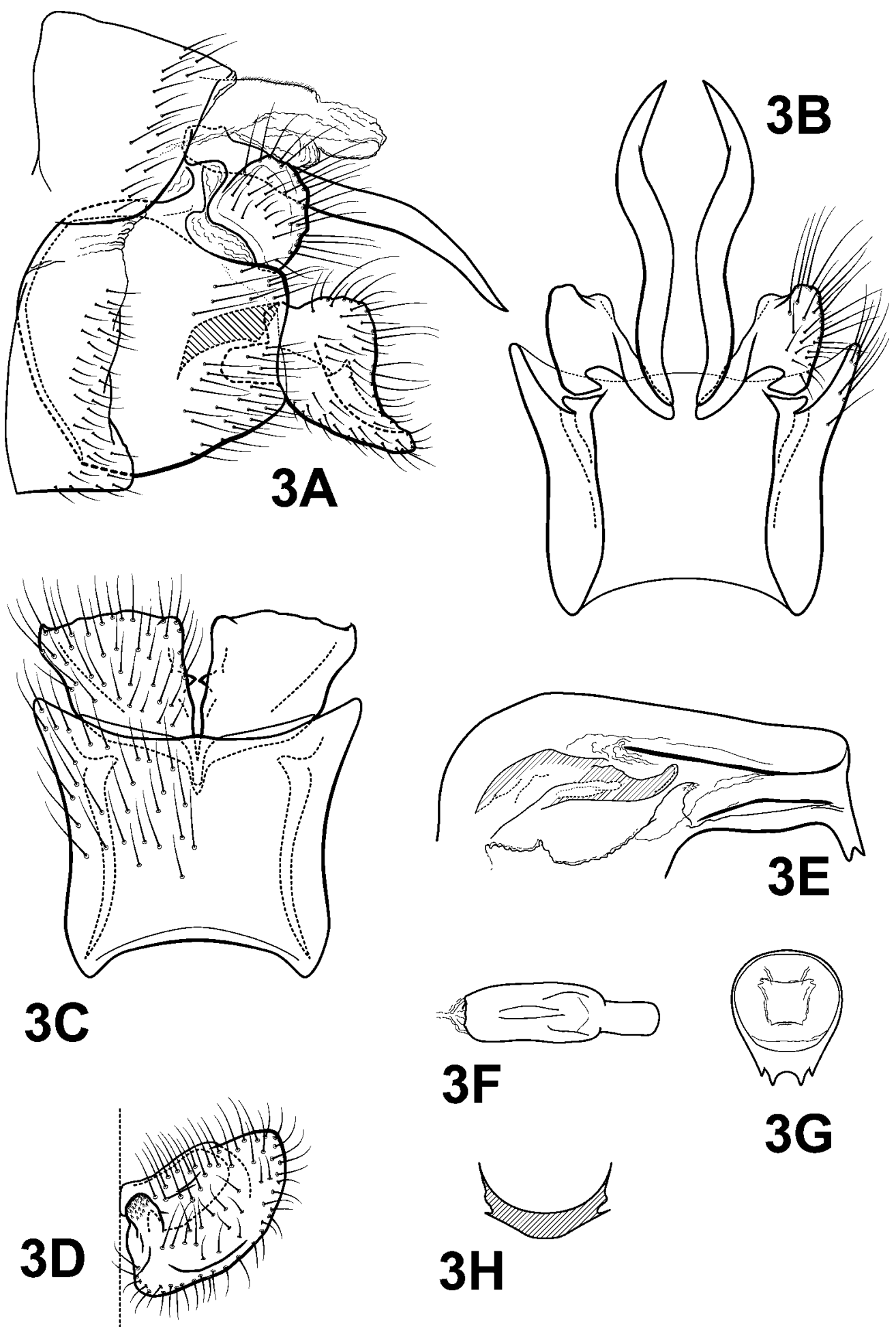

$3 \mathbf{G}$

FIGURE 3. Polycentropus quadricuspidis, new species. Male genitalia: A-lateral; B-dorsal; $\mathrm{C}$-ventral; D—inferior appendage, caudal; E-phallus, lateral; F-phallic sclerite, dorsal; Gphallobase, caudal; $\mathrm{H}$ - subphallic sclerite, caudal. 
appendage short, densely setose, rounded, broad basally; mesoventral process absent. Inferior appendage densely setose, short, subtriangular, wide dorsoventrally, subequal to length; dorsolateral flange broadly rounded; ventrally with dorsally-directed medial point, hidden in lateral view; in ventral view, inferior appendage quadrate; medial point prominent, acute; in caudal view, inferior appendage broadly oval, medial point rounded. Phallobase moderately elongate; apicoventral projection short, broad, with two pairs of points; phallic membranes without spines, but with ventromesal pair of conical, spiculate lobes and dorsal and ventral sclerotized bands; phallic sclerite elongate, apex upturned, spatulate. Subphallic sclerite U-shaped in caudal view.

Holotype male: ECUADOR: Zamora-Chinchipe: $30 \mathrm{~km}$ E Loja, el. 2000 m, 23 Sept. 1990, O.S. Flint, Jr. (NMNH).

Paratypes: Same data as holotype-1 male, 1 female (NMNH).

Etymology. From the Latin words quattuor, four, and cuspis, point, for the four points on the apicoventral area of the phallobase.

\section{Polycentropus silex Hamilton and Holzenthal, new species}

Fig. 4

This new Ecuadorian species is placed in the bartolus group based on the occurrence of a single large spine in the phallic membrane (Fig. 4E). The new species is very similar to $P$. ceciliae and $P$. fasthi in the shape of the inferior appendage (Fig. 4A, C \& D) and phallus (Fig. 4E \& F), but the presence of a nearly asetose, "thumb-like" lobe ventral to the setose body of the preanal appendage (Fig. 4A) distinguishes the new species from P. ceciliae and $P$. fasthi and from all other bartolus group species.

Adult. Length of forewing: male $6.0 \mathrm{~mm}(\mathrm{n}=1$, possibly teneral). Body stramineous, legs stramineous, dorsum of head and thorax pale brown, clothed with long stramineous setae; general vestiture of forewing with fine, light brown to brown setae, with many small, scattered areas of golden setae, base of forewing with long, erect setae.

Male. Genitalia as in Fig. 4. Sternum IX in lateral view subtriangular, dorsolaterally with distinct triangular patch of minute spicules, in ventral view quadrate; anterior margin shallowly concave, posterior margin slightly concave. Tergum IX and X membranous, slightly sclerotized basally. Intermediate appendage slightly curved, upturned, short, exceeding preanal appendage by $1 / 2$ its length; basal region complex, slightly expanded; apex acuminate, with preapical setae, in membranous sheathes. Preanal appendage short, bilobed, with setose thumb-like dorsal lobe and more digitate, asetose ventral lobe, broad basally; mesoventral process narrowly triangular, directed ventrad, apex hook-like. Inferior appendage densely setose, short, oval, dorsoventral height greater than length; dorsolateral flange broadly rounded; ventrally with dorsally-directed caudomesal point, exposed in lateral view; in ventral view, inferior appendage subtriangular, caudomesal point promi- 
nent, acute; in caudal view, inferior appendage suboval, caudomesal point broadly triangu-
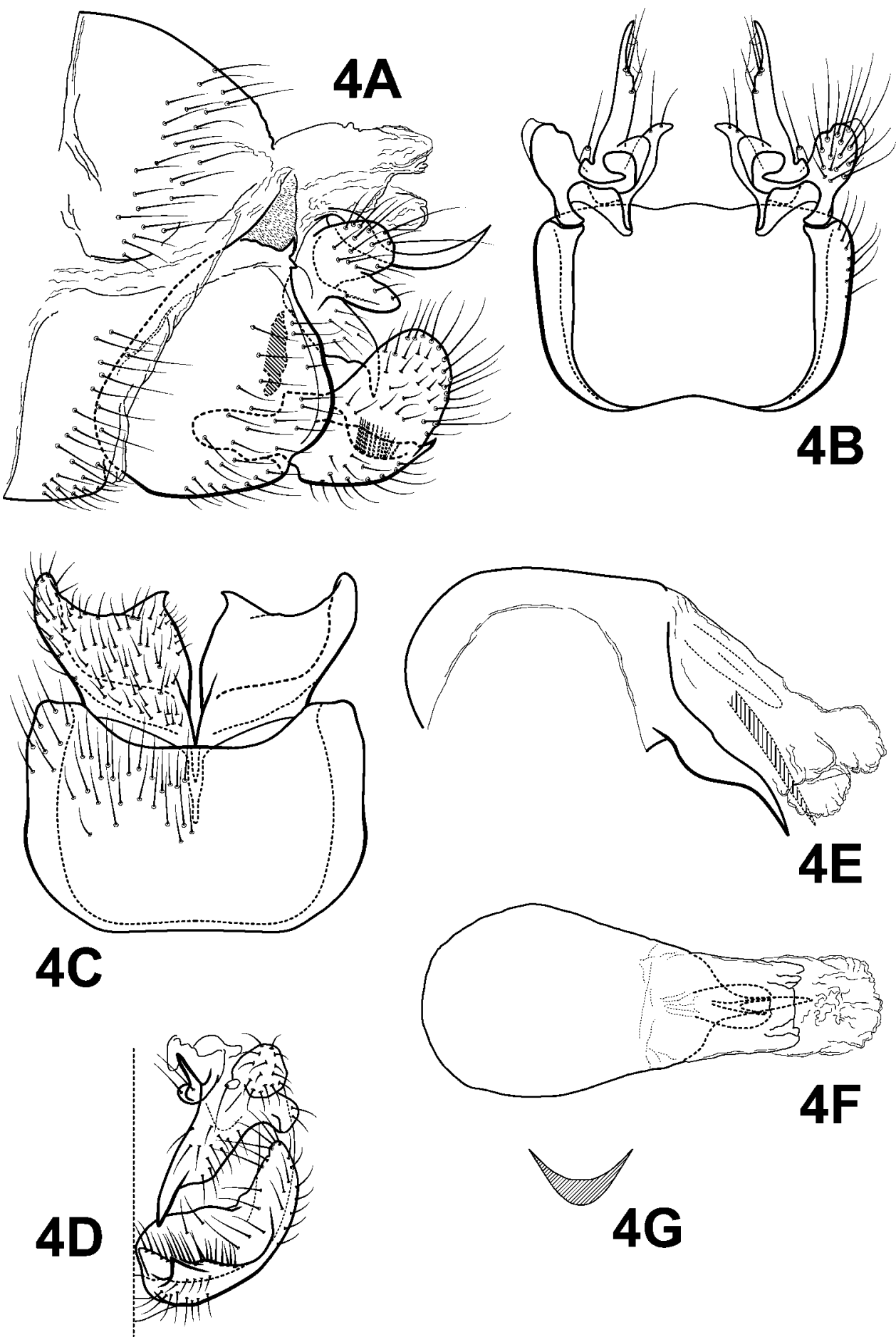

FIGURE 4. Polycentropus silex, new species. Male genitalia: A-lateral; B-dorsal; C-ventral; D—caudal; E-phallus, lateral; F-phallus, dorsal; G-subphallic sclerite, caudal. 
jection long, narrow, with single point; phallic membranes with single, long spine; phallic

sclerite oval (difficult to discern, especially apically). Subphallic sclerite U-shaped in caudal view.

Holotype male: ECUADOR: Pichincha: ca. 84 km SW Quito, Chiriboga Rd., el. 1400 m, 7 Sept. 1990, O.S. Flint, Jr. (NMNH).

Etymology. Silex is Latin for flint, a pure form of microcrystalline quartz (silicate) commonly found in limestone rock. We name this species "silex" to honor Dr. Oliver S. Flint, Jr. of the U.S. National Museum of Natural History, Washington, DC, for his many contributions to world trichopterology.

\section{Polyplectropus beccus Hamilton and Holzenthal, new species}

Fig. 5, 6

While wing venation indicates affinities to the New World Polyplectropus (Fig. 5), the male genitalia resemble no known New or Old World species of this genus (Fig. 6). The shape of the preanal appendage (Fig. 6A, B \& D) is unique among Polyplectropus, and to our knowledge all known polycentropodids. The 4, heavy and truncate setae on the dorsal lobe and the bifurcate posterior process of the preanal appendage (Fig. 6A \& B) are diagnostic. The phallus has a pair of large, symmetrical spines in the phallic membranes (Fig. 6E), an elongate phallic sclerite (Fig. 6E \& F), and a bluntly forked process in the apicodorsal phallic membranes (Fig. 6G). The inferior appendages (Fig. 6A, C \& D) resemble New World Polycentropus in the medial connection more than they resemble those of Polyplectropus, which are often broadly joined.

Adult. Length of forewing: male 5.5-6.5 mm ( $\mathrm{n}=3)$. Body pale brown to yellow, legs stramineous, dorsum of head and thorax brown, clothed with long, dark setae; general vestiture of forewing with fine brown to dark brown setae, with many small patches of golden setae, base of forewing with long, erect setae.

Male. Genitalia as in Fig. 6. Posteromesal region of tergum VIII produced posteriad, shelf-like, with apical patch of microsetae. Sternum IX in lateral view subquadrate, in ventral view quadrate; anterior margin emarginate, posterior margin slightly produced medially. Tergum IX and X membranous, very reduced. Intermediate appendage absent. Preanal appendage very short, densely setose, with patch of stout, blunt setae apically, rounded, broad basally; mesoventral process triangular, directed ventrad, apex bifurcate, beak-like, with sclerotized dorsal branch and more slender, less sclerotized, closely appressed ventral branch. Inferior appendage densely setose, elongate, dorsoventral height less than length; dorsolateral flange an elongate lobe; ventrally with short, lobate projection. Phallobase moderately elongate; apicoventral projection absent; phallic membranes with single pair of long, curved spines; phallic sclerite oval, moderately elongate, apicolateral corners acute. Subphallic sclerite absent, but subphallic semisclerotized band connecting bases of preanal appendages beneath phallus. 

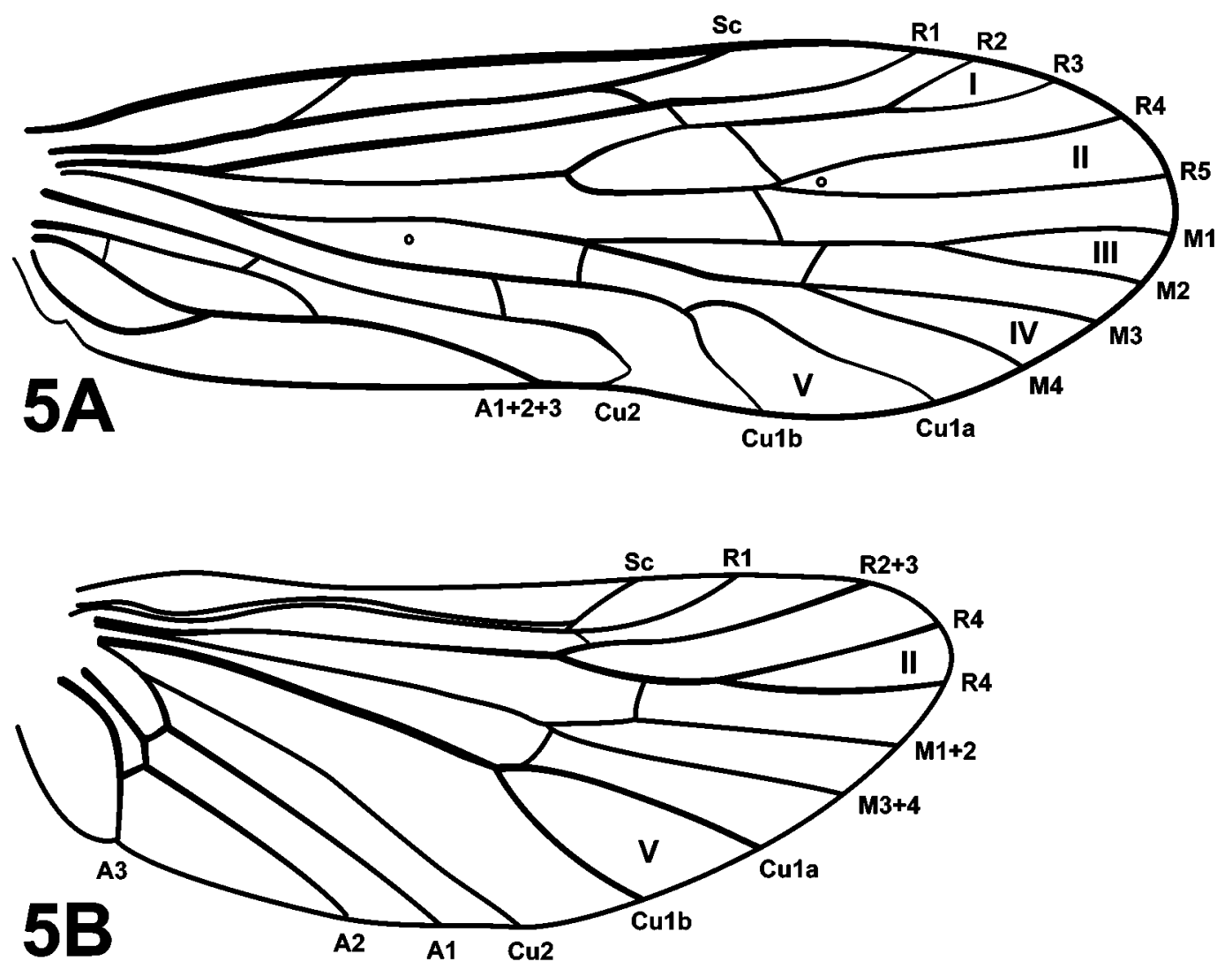

FIGURE 5. Polycentropus beccus, new species. Wings: A-forewing; B-hind wing.

Holotype male: VENEZUELA: T. F. Amazonas [=Estado Amazonas]: Puerto Ayacucho (40 km S), El Tobogan, Caño Coromoto, 24 January 1989, malaise, P.J. Spangler, R.A. Faitoute, C.B. Barr (NMNH).

Paratypes:VENEZUELA: T. F. Amazonas [=Estado Amazonas]: Puerto Ayacucho (29 km S), Río Agua Blanca, 17 November 1987, P.J. Spangler, R.A. Faitoute-1 male (NMNH); same data as holotype-1 male (UMSP).

Etymology. From beccus, Latin for beak or bill, referring to the bifurcate process of the preanal appendage that resembles a birds beak in lateral aspect.

FIGURE 6. Polycentropus beccus, new species. Male genitalia: A-lateral; B-dorsal; C-ventral; D—caudal; E—phallus, lateral; F—phallic sclerite, dorsal; G—phallobase, caudal; H-VIIIth tergite, dorsal. 

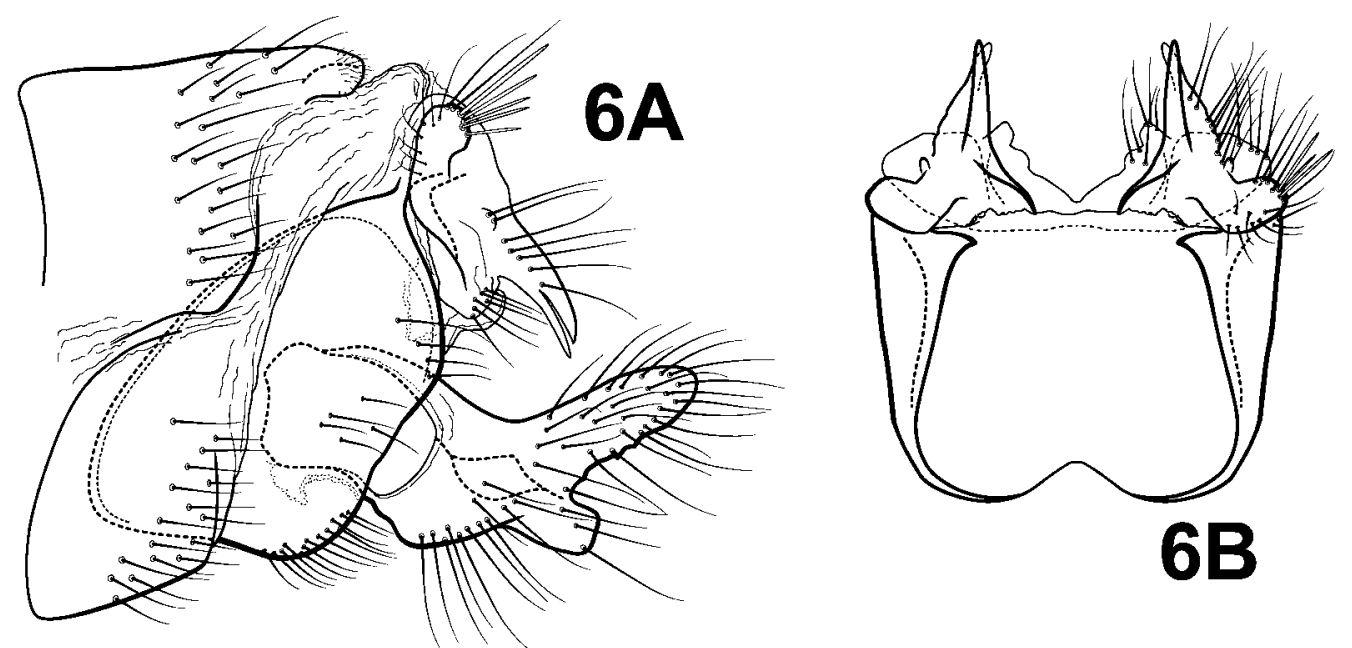

ZOOTAXA
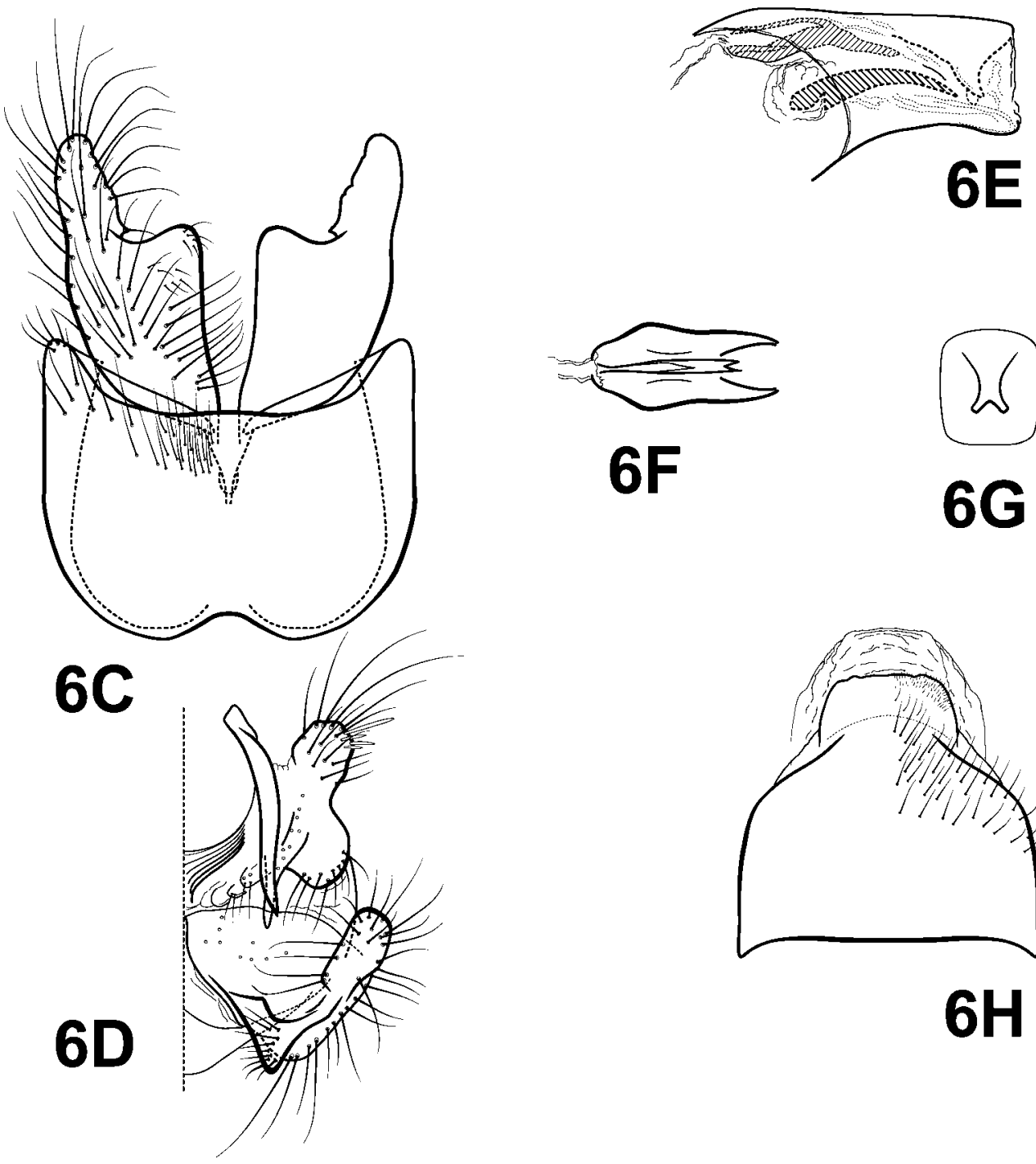

6G

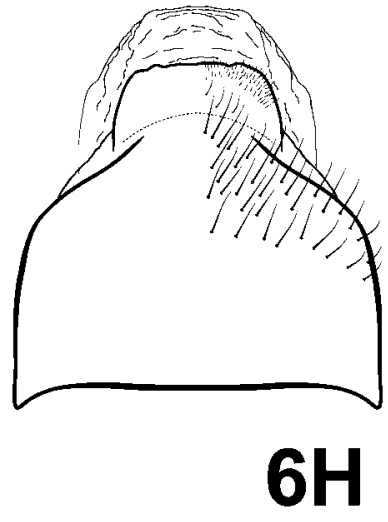


We thank Dr. Oliver S. Flint, Jr., National Museum of Natural History, Smithsonian Institution, for bringing these new and interesting polycentropodids to our attention. Maria Lourdes Chamorro-Lacayo, University of Minnesota, provided valuable assistance in determining the identity of the new Polyplectropus and sharing her views on polycentropodid relationships. We thank Dr. Roger J. Blahnik, University of Minnesota, for his helpful comments during the preparation of this manuscript. We also appreciate the comments of two anonymous reviewers. The senior author gratefully acknowledges the support of the Center for Field Biology, Austin Peay State University, for support during trips to Minnesota to work on Neotropical polycentropodids. This material is based upon work supported by the National Science Foundation under Grant Nos. 9971885 and 0117772. Additional support was provided by the University of Minnesota Insect Collection under projects AES MIN-17-014 and 017. This support is gratefully acknowledged.

\section{LITERATURE CITED}

Chamorro-Lacayo, M.L. (2003) Seven new species of Polycentropodidae (Trichoptera) from Nicaragua and Costa Rica. Proceedings of the Entomological Society of Washington, 105, 484498.

Chamorro-Lacayo, M.L. \& Holzenthal, R.W. (2004) Studies of Neotropical Polycentropodidae. Bulletin of the North American Benthological Society, 21, 177.

Chamorro-Lacayo, M.L. \& Holzenthal, R.W. (2003) Seven new species of Polyplectropus Ulmer (Trichoptera: Polycentropodidae) from Costa Rica. Proceedings of the Entomological Society of Washington, 106, 202-216.

Flint, O.S., Jr., Holzenthal, R.W. \& Harris, S.C. (1999) Catalog of the Neotropical caddisflies (Insecta: Trichoptera). Special Publication, Ohio Biological Survey, Columbus, Ohio, 239 pp.

Flint, O.S., Jr. \& Sykora, J.L. (2004) Caddisflies of Hispaniola, with special reference to the Dominican Republic (Insecta: Trichoptera). Annals of Carnegie Museum, 73, 1-60.

Hamilton, S.W. (1986) Systematics and biogeography of the New World Polycentropus sensu stricto (Trichoptera: Polycentropodidae). Ph.D. dissertation, Clemson University, Clemson, South Carolina, $257 \mathrm{pp}$.

Holzenthal, R.W. \& Andersen, T. (2004) The caddisfly genus Triaenodes in the Neotropics (Trichoptera: Leptoceridae). Zootaxa, 511, 1-80.

Holzenthal, R.W. \& Almeida, G.L., de. (2003) New species of Polycentropodidae (Trichoptera) from southeastern and southern Brazil. Proceedings of the Entomological Society of Washington, 105, 22-29.

ITIS. (2002) Integrated Taxonomic Information System, last updated 20 August 2002. United State Department of Agriculture, Washington, District of Columbia. Available from http:// www.itis.usda.gov (accessed 5 August 2004)

Morse, J.C. (2001) Trichoptera World Checklist, 08-Jan-2001, website (version 1.0). Clemson University, Clemson, South Carolina. Available from http://entweb.clemson.edu/database/trichopt/ (accessed 4 August 2004) 